\title{
Cat Scratch Disease- A Case Report
}

\author{
B H N Yasmeen ${ }^{1}$, R A Jahan ${ }^{2}$, S Ahmed ${ }^{3}$, M Hussain ${ }^{4}$, A U Khan ${ }^{5}$, J A Begum ${ }^{6}$, M M Hoque ${ }^{7}$
}

\section{Dr. B H Nazma Yasmeen MBBS, MCPS, MD (Paed) Associate Professor Dept. of Paediatrics Northern International Medical College Dr. Rowshan Akhter Jahan MBBS, DCH (Paed)} Medical Officer, MD part-II student

3 Dr. Shafi Ahmed Assistant Professor Dept. of Paediatrics Northern International Medical College

${ }^{4}$ Dr. Mahfuza Hussain MBBS, DDV

Junior Consultant

${ }^{5}$ Dr. Abbas Uddin Khan

MBBS, MD (Paed)

Associate Professor

Dept. of Paediatrics

Taiyerunnesa Medical College

${ }^{6}$ Dr. Jostna Ara Begum MBBS, MD (Paed)

Associate Professor

${ }^{7}$ Dr. Md. Mahabubul Hoque MBBS, FCPS (Paed) Associate Professor Dept. of Neonatology

$2,4,6,7$

Dhaka Shishu (Children) Hospital

\section{Correspondence}

Dr. B H Nazma Yasmeen

Associate Professor

Dept. of Paediatrics

Northern International Medical

College, Dhaka

Mobile: 01711662272

e mail: drnazmayasmeen@yoaho.com

\section{Abstract}

We are reporting a case of a 10 year old boy admitted in Dhaka Shishu (Children) hospital with the complaints of -swelling of both side of inguinal region for 2 months, tenderness of the same area for 1 month and low grade fever for 2 months. With the history and physical examination of the patients our differential diagnosis was Tuberculosis/Lymphoma/Cat scratch disease (CSD). He had only a history of contact with a kitten for 1 week 3 months back but no history of cat scratch or bite. Lymph node biopsy revealed that it was a case of Cat scratch disease.

\section{Introduction}

Cat scratch disease (CSD) also known as "Cat scratch fever" or "Subacute regional lymphadenitis" ${ }^{1}$ is a usually benign infectious disease caused by the intracellular bacterium Bartonella henselae. It is most commonly found in children following a scratch or bite of a cat by about one to two weeks. It was first discovered in 1889 by Henri Parinaud. ${ }^{2}$ It occurs worldwide with no racial or sex predilection.

Kittens are more likely to carry the bacteria in their blood, and may therefore be more likely to transmit the disease than are adult cats. However, the results of experimental studies showed that fleas serve as a vector for transmission of $B$. henselae among cats. ${ }^{3}$ Although this disorder is strongly associated with cats, other animals have also been implicated. Reports also be found of transmission by dogs, rabbits, and monkeys. A few anecdotal cases have also been described involving transmission by porcupine quills and fish bones. Transmission occurs by scratching, biting or possibly even licking. Kittens seem to be particularly common as vectors.

\section{Case History}

A 10 year old previously healthy boy from a slam area admitted in Dhaka Shishu (Children) hospital with the complaints of -swelling of both side of inguinal region for 2 months, tenderness of the same area for 1 month and low grade fever for 2 months.

Two months back he first noticed bilateral swelling of his both ingunal region and initialy it was hard and nontender. He also complaints of low grade intermittent fever for the same duration. Ultimately the size of swelling increased and its consistency changed to soft and it became tender as an abcess for the last 1 month. He did not get any treatment for these problems. The boy was fully immunized and BCG mark was present. There was no history of contact with TB patient, gradual weight loss, night sweating; no abdominal pain and abdominal fullness.
He did not notice similar swelling anywhere of his body and recalled a history of contact with a kitten 3 months back. At that time he was circumcized and cofined to home for 7 days and used to play with a kitten on his bed. But there is no history of cat scratch or bite on his lower limbs. After that, he never went to any contact with any cat or kitten.

\section{On physical examination}

The boy was cachetic (anthropometric measurements were-hight- $120 \mathrm{~cm}$, weight- $17 \mathrm{~kg}$, OFC- $48 \mathrm{~cm}$ ) and febrile. He was mildly pale and vital signs were within normal limit. Abdomen was soft and nontender without organomegaly or palpable masses. Both the ingunal lymphnodes were palpable but no other lymphnodes (especially supraclavicular, axillary or popliteal) were palpable. No mark of cat scratch or bite was present on his lower limbs. Other systemic examinations revealed no abnormality.

\section{On local examination of the inguinal region}

An obvious erythomatous swelling was found on the left side and relatively smaller swelling was found on the right side. Bilateral lymphnodes were palpable, which was warm, tender, erythematous and without surrounding cellulitis, soft in consistency with minimal fluctuance was detected. Lymphnodes were not fixed with the above and underlying structures, the nodes were free. On the left side single large lymphnode of about $3.5 \mathrm{~cm} \times 2.5 \mathrm{~cm}$ and on the right it was about $3.0 \mathrm{~cm} \times 2.0 \mathrm{~cm}$. His range of motion of the lower limbs were decreased due to tenderness and volume of the masses.

Several relevant investigations were done and laboratory data revealed a moderate leukocytosis of $12,100 / \mathrm{mm}^{3}$ (neutrophils $64 \%$ without bands, lymphocytes $30 \%$, monocytes $02 \%$, eosinophils 04\%).Peripheral blood flim shows normocytic normochromic RBC, WBC and platelets are normal. MT-negative $(0 \mathrm{~mm})$, X-ray chest-normal, Blood group-B+ve. USG of the swelling revealed Lymph node $(3.3 \mathrm{~cm} \times 2.4 \mathrm{~cm}$ left and on the right it is $3.1 \mathrm{~cm} \times 2.0 \mathrm{~cm})$ containing fluid suggestive of an abscess.

Given the history of contact with a kitten and the above findings the most probable diagnosis was Cat Scratch Disease. However, persistent and progressive lymphadenopathy pointed toward the need for an immediate biopsy in order to rule out Tuberculosis and Lymphoma and other infections (staphylococcal and streptococcal). 
Finally incision and drainage of bilateral inguinal abscess were done by the Paediatric Surgeon. Thick pus was drained. Pus was sent for gram and AFB stain and culture. No bacteria was found in Gram and AFB stain. Cultures were negative. Abscess wall send for histopathological examination and Histopathological reports was as follows- 'Section shows the lymphnode and soft tissue. The node reveals suppurative granuloma which consists of central necrotic area infiltrated with neutrophils, surrounded by epitheloid cells. The remaining nodal tissue shows follicular hyperplasia with germinal centers. The soft tissue also shows the same features along with proliferation of fibrous tissue. Diagnosis suggestive of Cat scratch disease.'
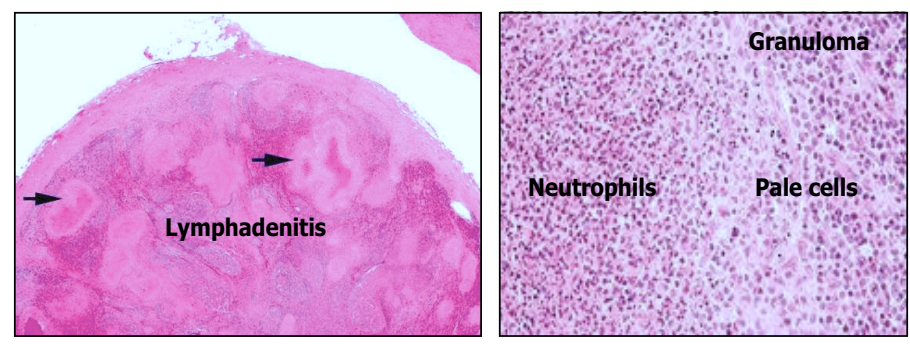

Histopathological examination

The patient completed treatment with azithromycin for -7 days. Over the next 2-3 weeks, the lymphadenopathy began to subside and almost disappeared after three months.

\section{Discussion}

Inguinal lymphadenopathy can occur due to various causes which show significant overlap in clinical presentation and clinical examination. Persistent and progressive inguinal lymphadenopathy pointed to rule out Tuberculosis, Lymphoma, other infections (staphylococcal and streptococcal) as well as Cat scratch disease. CSD is common, with more than 24,000 estimated cases per year in the USA. ${ }^{4}$ Most $(87-99 \%)$ patients have had contact with cats, many of which are kittens $<6$ mo of age, and $>50 \%$ have a definite history of a cat scratch or bite. ${ }^{4}$ Though there is no epidemiological data of CSD available in our country.

Manifestations of cat scratch disease can be divided into 2 groupsclassic and atypical.

Classic cat scratch disease presents as tender and swollen regional lymphadenopathy. There may be a papule at the site of initial infection. While some patients have fever and other systemic symptoms, many do not. Other associated complaints include headache, chills, backache and abdominal pain. It may take 7 to 14 days, or as long as two months, before symptoms appear. Most cases are benign and selflimiting, but lymphadenopathy may persist for several months after other symptoms disappear. Spontaneous resolution is expected in 2-3 months.

Atypical CSD found several different forms depending on organ systems involved. e.g-

- Parinaud's oculoglandular syndrome- is a granulomatous conjunctivitis with concurrent swelling of the lymph node near the ear.

- Optic neuritis- involvement of the retina, and neuropathy can also occur.

- Some forms most-often affects patients with HIV and other conditions causing severe immune compromise. e.g-Bacillary peliosis (the liver and spleen are primarily affected, with findings of blood-filled cystic spaces on pathology). ${ }^{5}$

- Bacillary angiomatosis- is primarily a vascular skin lesion that may extend to bone or be present in other areas of the body.

- Acute encephalopathy-can occur. The New York Times Magazine described a case, presenting as a meningitis, with fever, headache, and impaired vision. ${ }^{6}$

Despite the severity of initial presentation in Atypical CSD, patient outcome can be favorable.

The diagnosis of B. henselae infection is clinical, with laboratory evaluation to confirm the initial suspicion. ${ }^{7}$ Isolation of $\mathrm{B}$. hensellae provides a definitive diagnosis but it is very difficult to isolate the bacterium from tissue and most patients are not bacteremic. Additional testing such as the B. hensellae antibody test, Warthin-Starry stain, PCR may be used as an adjunct to the diagnosis. Under the microscope, the skin lesion (a red papule at site of inoculation, may become pustular or crusted) demonstrates a circumscribed focus of necrosis, surround by histiocytes, often accompanied by multinucleated giant cells, lymphocytes and eosinophils. The regional lymph nodes demonstrate follicular hyperplasia with central stellate necrosis with neutrophils, surrounded by palisading histiocytes (suppurative granulomas) and sinuses packed with monocytoid B cells, usually without perifollicular and intrafollicular epithelioid cells.

In case of classic CSD spontaneous resolution is expected within 2-3 months. Whether immunocompetent individuals with CSD need treatment is debatable since the natural progression is for complete recovery within a few months. However, systemic antibiotics do seem to shorten the disease duration. ${ }^{7}$ Data from the current literature for treatment of CSD are obtained only from small series and case reports. The current recommendations for non life threatening CSD include a short course - 5 days- of azithromycin, with alternatives including clindamycin, rifampin, trimethoprim/sulfomethoxazole and ciprofloxacin.

\section{Conclusion}

The most common presentaion of B. henselae infection is CSD and it is the most common cause of chronic lymphadenitis that persists for $>3$ week. Distribution of CSD is worldwide and infection occurs in all races. There is no epidemiological data of CSD available in our country. Therefore prevalence of CSD in our country is unknown. Fortunately it is self-limited and no specific treatment is necessary. If treatment is considered the current recommendations for non life threatening CSD include a short course- 5 days-of azithromycin, with alternatives including clindamycin, rifampin, trimethoprim/sulfomethoxazole and ciprofloxacin. In this case azithromycin was given and patient followed up for 3 months. All symptoms regresses by this time.

\section{References}

1. Rapini, Ronald P, Bolognia, Jean L., Jorizzo, Joseph L. Dermatology: 2-Volume Set. St. Louis: Mosby. ISBN 1-4160-2999-0.

2. Jerris RC, Regnery RL (1996). "Will the real agent of cat-scratch disease please stand up?" Annu. Rev. Microbiol. 50: 707-25

3. Chomel BB, Kasten RW, Floyd-Hawkins K, et al. "Experimental transmission of Bartonella henselae by the cat flea". J. Clin. Microbiol. August 1996. 34 (8): 1952-6.

4. Stechenberg BW. Cat-Scratch Disease (Bartonella henselae). In: Kliegman RM, Stanton BF,St. Geme III JW, Schor NF, Behrman RE, editors, Nelson textbook of Pediatrics. $19^{\text {th }}$ edition. Pheladelphia, PA: Saunders,2011:983-86.

5. Perkocha LA, Geaghan SM, Yen TS, et al. "Clinical and pathological features of bacillary peliosis hepatis in association with human immunodeficiency virus infection". N. Engl. J. Med. December 1990.323 (23): 1581-6.

6. Sanders, L. "Vision Quest", "The New York Times", 4/10/2009.

7. Florin TA, Zaoutis TE, Zaoutis LB. Beyond cat scratch disease: widening spectrum of Bartonella henselae infection. Pediatrics. 2008;121(5):e1413-25. 